\title{
Comparison of Triamcinolone Versus Platelet Rich Plasma Injection for Improving Trismus in Oral Submucous Fibrosis
}

Amer Sabih Hydri, Iqbal Hussain Udaipurwala, Nadeem Ahmed Sheikh, Sana Muhammad Sadiq, Sohail Aslam, Syed Muhammad Asad Shabbir Bukhari

\begin{abstract}
:
Objective: To compare the effect of Triamcinolone versus Platelet Rich Plasma (PRP) injection intraorally for improving trismus in Oral Submucous Fibrosis (OSMF).
\end{abstract}

Study Design and setting: Randomized double-blind comparative study, conducted at ENT department of PNS Shifa Hospital, Karachi from 1st June 2015 to 30th June 2016.

Methodology: Eighty patients with trismus due to oral submucous fibrosis were divided randomly into two groups, 'A' and 'B' of 40 patients each. In Group A, Inj. Triamcinolone 40mg (1 ml) was injected into the sub-mucosal plane in the retro-molar trigone area and into the fibrous bands along the soft palate on multiple sites, weekly for 6 weeks. In group B Inj. PRP $1 \mathrm{ml}$ weekly was administered for 6 weeks along the same site. Vernier calipers were used to precisely measure the Maximum Interincisal Distance (MIID) in cms before and after the treatment.

Result: There was a male preponderance in the study group with a male to female ratio of 5.1:1. In group 'A' mean pretreatment MIID was $2.3 \pm 0.7 \mathrm{cms}$, while in group 'B', it was $2.2 \pm 0.5 \mathrm{cms}$. After completion of 6 weeks treatment the mean MIID improved in group 'A' to $3.08 \pm 0.8 \mathrm{cms}$, and in group 'B' to $3.22 \pm 0.5 \mathrm{cms}$. The mean improvement in MIID in group 'A' was $0.783 \pm 0.25 \mathrm{cms}$ compared to $1.01 \pm 0.05 \mathrm{cms}$ in group 'B' ( $\mathrm{p}<0.05)$.

Conclusion: Intraoral injection of PRP is more effective than Triamcinolone in improving trismus due to OSMF.

Key Words: Injection, Oral Sub Mucosal Fibrosis, Platelet rich Plasma, Trismus, Triamcinolone.

\section{INTRODUCTION:}

Oral sub mucous fibrosis (OSMF) is a potentially malignant condition of the oral cavity resulting in increasing loss of tissue mobility, marked rigidity and an eventual restricted ability to open the mouth. It may progressively affect the entire oral cavity, and occasionally the pharynx, causing a gradual reduction in mouth opening. It's association with other premalignant conditions like leukoplakia and lichen

Amer Sabih Hydri

Professor, Head of ENT department

P.A.F Hospital, E-9, Islamabad

Iqbal Hussain Udaipurwala

Professor, Head of ENT department,

I Bahria University Medical and Dental College and PNS Shifa Hospital Karachi.

I Nadeem Ahmed Sheikh

Assistant Professor, Department Of ENT,

Combined Military Hospital, Abbottabad.

Sana Muhammad Sadiq

I Assistant Professor, Department Of ENT,

I Bahria University Medical and Dental College and PNS Shifa

Hospital, Karachi.

Email: sanaent1112@gmail.com

Sohail Aslam

Assistant Professor, Department Of ENT,

I Hospital, Karachi.

I Syed Muhammad Asad Shabbir Bukhari

I Assistant Professor, Department Of ENT,

Bahria University Medical and Dental College and PNS Shifa

I Hospital, Karachi

Received: 25-09-2019

I Accepted: 30-12-2019 planus has also been noted. There is a considerable variation in its rate of transformation to malignancy, ranging from $3 \%$ to $19 \%^{1,2}$. The pathogenesis of OSMF is complex and incompletely understood. It has a strong link to areca nut (betel nut) chewing. The other proposed etiological factors include excessive chilly consumption, vitamin B12 and iron deficiency, tobacco ingestion, smoking, autoimmunity, genetic and environmental factors ${ }^{3,4,5}$.

The disease begins with vesicle formation, followed by inflammation and increasing hyalinization of the lamina propria. This results in extensive fibrosis of the subepithelial as well as submucosal tissue which represents as thick, vertical bands in the cheeks, faucial pillars and even surround the lips causing trismus and difficulty in protrusion of the tongue. The blanching of oral mucosa is due to impaired local vascularity, imparting it a marble like appearance ${ }^{6}$. The most commonly involved site is buccal mucosa, followed by palate, retro molar region, faucial pillars and pharyn $x^{7}$. Consequently, in advanced stages, OSMF leads to dysphagia and difficult phonation. The resultant limited access to the oral cavity eventually causes malnutrition and poor oral hygiene. The severity of trismus can be graded by measuring the distance between the upper and lower incisors while the mouth is opened to the maximum. The mouth opening is categorized into stage I $(>3 \mathrm{~cm})$, stage II $(2-3 \mathrm{~cm})$, and stage III $(<2 \mathrm{~cm})^{8,9,10}$.

Treatment of oral submucous fibrosis is based on medical and surgical management along with physiotherapy. Conventional medical management includes avoidance of 
Amer Sabih Hydri, Iqbal Hussain Udaipurwala, Nadeem Ahmed Sheikh, Sana Muhammad Sadiq et.al.

irritating substance like betel chewing, tobacco ingestion or smoking etc. and involves regular administration of corticosteroids, either via submucosal injections or topical application. Steroids, in addition to inhibition of production of phospholipase A2; resulting in reducing the production of prostaglandins and leukotriene, stabilize lysosomal membranes and prevent the release of proteolytic enzymes as well. Several glucocorticoids are used for the treatment of OSMF such as short-acting (hydrocortisone) intermediate acting (triamcinolone), and long-acting glucocorticoids (betamethasone and dexamethasone) ${ }^{11}$. Recently plateletrich plasma (PRP) treatment is gaining popularity in oral and dental surgery ${ }^{12,13}$. Its use in alleviating trismus in OSMF however hasn't been published. Platelet-rich plasma is the autologous component of the plasma and contains higher concentrations of platelets, growth factors, and cytokines than the basal levels ${ }^{14}$.Platelet rich plasma is an element of whole blood, prepared through centrifugation to a concentrated form. It is processed with an activating agent and then finally injected into the oral submucosa. Platelet rich plasma acts by inducing the platelets to secrete proinflammatory mediators and growth factors. These, in turn, initiate the cascade of wound healing and bring about tissue remodeling. It was suggested that the acceleration of the process of wound healing by PRP depended on the synergistic effects of these growth factors.

The effectiveness of triamcinolone acetonide versus plateletrich plasma in improving trismus is not documented in local literature. Our study is a pilot study which sets out to determine which treatment is more efficacious in effectively improving trismus due to oral submucous fibrosis.

\section{METHODOLOGY:}

This study was conducted at the department of Otorhinolaryngology, Head \& Neck surgery, PNS Shifa Hospital, Karachi, over a period of one year from June 2015 to June 2016. After obtaining ethical clearance for the study from the Hospital Ethical Committee, each patient included was informed about the treatment protocol and informed consent was obtained. Consecutive convenient sampling technique was employed and a total of eighty patients were included for this study. The patients included in the study were of either gender, of any age, with a clinical diagnosis of OSMF, having burning sensation on eating spicy food, presence of palpable fibrous bands on the soft palate and having restricted mouth opening. The exclusion criteria were those who had undergone any other treatment for OSMF, those with temporo-mandibular joint disorders, any systemic disease, those who were allergic to local drugs, those with trismus due to other causes and those with other pre-malignant lesions like leukoplakia.

This was a double-blind study where not the patient and nor the performer were aware of the group. Patients were randomly divided in to two groups, 'A' and ' $\mathrm{B}$ ' of 40 patients each. In group A, injection Triamcinolone 40mg (1 ml), filled in an insulin syringe, was injected intraorally in the sub mucosal plane, into the retro-molar trigone and in the fibrous band along the soft palate on multiple sites, weekly for 6 weeks. Patients of group B were administered Inj. PRP $(1 \mathrm{ml})$ weekly for 6 weeks along the same sites. The MIID was precisely measured with a Vernier calipers initially, before commencing the treatment, and subsequently on all visits. Following the completion of treatment these patients were followed up monthly for a period of 9 months. Enquiry about symptomatic subjective improvement was done and precise documentation of MIID was carried out in all these visits. Data was entered and statistical analysis was done using the SPSS version 23 and a p-value of less than 0.05 was considered significant.

\section{RESULTS:}

A total of 80 patients included in our study and divided randomly into two groups; 'A' and 'B', consisting of 40 patients each. Overall, there were 67 males and 13 females in total study group, with a male to female ratio of 5.1:1. The male preponderance was evident in almost the same ratio in both groups; 33 males and 07 females in Group 'A', and 34 males and 06 females in group ' $\mathrm{B}$ '. The mean age of total patients was found to be $24.65 \pm 4.6$ with a minimum of 16 and maximum of 37 years. In Group 'A' the age ranged from 16 to 37 years with a mean of $24.38 \pm 4.9$ years. In Group B the age ranged from 18 to 33 years with a mean age of $24.93 \pm 4.3$ years.

All patients had a positive history of using areca nut ('Chaliya' or 'Supari') either alone or in different combinations including Gutka and Paan. Betel nut alone was used by 36 patients (45\%) followed by 'Gutka' in 29 patients (36.2\%) and pan in 15 patients (18.8\%) (Fig 3).In group A, 19 patients (47.5\%) were using betel nut alone, 14 (35\%) using Gutka and 7 (17.5\%) were eating Paan. In Group B, 17 patients (42.5\%) were using betel nut, 15 (37.5\%) Gutka and 8 (20\%) were eating Paan. These patients were using these substances from 6 months to 20 years with a mean time duration of $7.725 \pm 3.7$ years. In group A the mean duration of use was $8.07 \pm 4.7$ years $(0.5$ to 20 years $)$, while in Group B it was $7.38 \pm 2.58$ years ( 3 to 12 years). 66 patients $(82.5 \%$ ) had stopped taking these substances with the mean duration of stopping was $88.75 \pm 29$ days. Surprisingly 14 patients $(17.5 \%)$ has not stopped taking these substances, with a count of 7 patients in each group.

In group ' $A$ ' mean pre-treatment MIID was $2.3 \pm 0.7 \mathrm{cms}$, while in group ' $\mathrm{B}$ ', it was $2.2 \pm 0.5 \mathrm{cms}$. After completion of 6 weeks treatment the mean MIID improved in group ' $A$ ' to $3.08 \pm 0.8 \mathrm{cms}$, and in group ' $\mathrm{B}$ ' to $3.22 \pm 0.5 \mathrm{cms}$. The mean improvement in MIID in group 'A' was $0.783+/$ $0.25 \mathrm{cms}$ compared to $1.01+/-0.05 \mathrm{cms}$ in group ' $\mathrm{B}$ '. The resultant $\mathrm{P}$ value was 0.0124 which is statistically significant. 
Fig 1: Etiological factors of OSMF

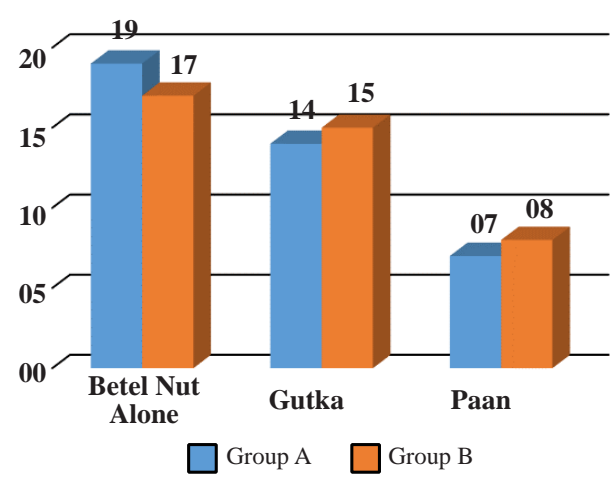

Fig 2: Pre and post treatment MIID readings with Mean Improvement in centimeters in both groups.

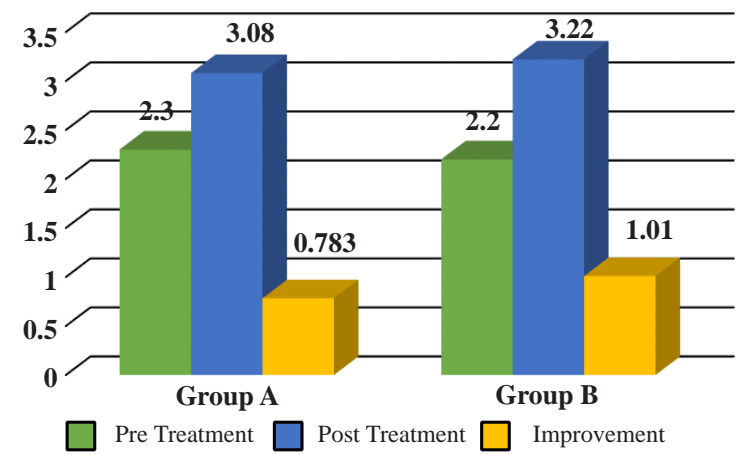

\section{DISCUSSION:}

Over the last 2-3 decades there has been an exponential increase in the manufacturing of attractive areca nut products, Gutka or Paan Masala with an escalating consumption in the younger generation, ultimately leading to an increased incidence of $\mathrm{OSMF}^{15}$. There is a multitude of non-surgical methods of management of OSMF. They include Corticosteroids, Proteolytic enzymes, Vitamins, Levamisole, Placental extract, Interferon-Ý, peripheral vasodilators and ayurvedic medicines ${ }^{16}$. Many studies have used various combinations of either short acting, intermediate or long acting steroids with hyaluronidase ${ }^{17}$. Generally, a review of published studies reveals a male predominance ${ }^{18,19,20}$ except one odd study with opposing results ${ }^{16}$. In a study conducted in Karachi Pakistan, male to female ratio was found 7:1 showing the male preponderance in this group of Pakistani population $^{21}$. This is commensurate with the findings of 5.1:1 in our study.

Patients using areca nut products are generally young adults, as evinced in a study from Allahabad, India, where $46 \%$ patients were in their 3 rd decade of life ${ }^{7}$.This is similar to the findings of our study where the mean age was 24.65 years. According to a study conducted by Hazarey et.al ${ }^{22}$ $77.8 \%$ patients were consuming multiple products, whereas
$20.5 \%$, patients were having oral consumption of a single product. Mean duration of substance abuse was $1.4 \pm 3.59$ years. This is in contrast with our study where only $17.5 \%$ $(\mathrm{n}=14)$ patients were consuming multiple products. While mean duration of coral consumption was 7.7 (3.7) years.

Injection Triamcinolone proved to be superior to placental extract ${ }^{23}$ and Dexamethasone ${ }^{24}$ but when compared with other preparations like oral colchicine ${ }^{25}$ and Lycopene ${ }^{26}$ failed to give fruitful results. Platelet-rich plasma (PRP) is a new approach to tissue regeneration and it is becoming a valuable adjunct to promote healing in many procedures in different fields of medicine and surgery. PRP was first used in 1987 by M. Ferrari after an open-heart surgery ${ }^{27}$. Now, it is widely used in various fields of medicine and surgery including plastic surgery, otorhinolaryngology, neurosurgery, urology, dermatology, general surgery, gynecology and obstetrics. In 1997 Whitman et al presented the use of PRP in oral surgery. This biological treatment mimics the natural pathways of wound healing by driving to the injury site the whole protein array of PRGF (plasma rich in growth factors) to repair the damaged tissues, thus it accelerates bone repair, promotes fibroblast proliferation, and increases tissue vascularity $^{28}$. PRP has a platelet concentration above baseline. Normal platelet counts in blood range between $150,000 / \mu 1$ and $350,000 / \mu 1$ and average about $200,000 / \mu 1$ but according to scientific proofs PRP provides up to $1,000,000$ platelets $/ \mu 1$ locally, in a 5-ml volume of plasma which is the working definition of PRP today ${ }^{29}$, thereby increases the concentration of growth factors and platelets by 5 to 10 times the normal amount. A small amount of patient's blood is drawn i.e. up to $20-50 \mathrm{cc}$ and sent to the laboratory for processing in centrifuge machine. Before applying injections, topical anesthesia is given, although it is a mild procedure but some patients might complain of slight discomfort to burning sensation at the site of needle prick. Being autologous, it is free from hazard of allergic reactions or transfer of contagious diseases.

A review of medical literature reveals that to date there is no published study either documenting the use of PRP in managing OSMF nor comparing its effect with intralesional steroids. Although there are no similar studies, yet a fair idea of improvement in MIID can be gauged by comparing the results of different studies. Regarding PRP, in dentistry several studies have been done for treatment of chronic inflammatory diseases and those which aid in bone regeneration in postoperative cases of alveolar or jaw diseases. In otorhinolaryngology, use of PRP as a biological graft material for repair of tympanic membrane perforation, was used which gave $100 \%$ success rate. An improvement in MIID of $4.3 \pm 0.8 \mathrm{~mm}$, after biweekly Injections of $1.5 \mathrm{ml}$ Dexamethasone and 1500 I.U Hyaluronidase for 6 weeks; $;^{30}$ $6 \pm 2 \mathrm{~mm}$ after biweekly Injections of $1.5 \mathrm{ml}$ Dexamethasone and 1500 I.U Hyaluronidase for 4 weeks ${ }^{18}, 9.38 \mathrm{~mm}$ after 8 weeks treatment of intralesional Hyaluronidase injection ${ }^{19}$, 
Amer Sabih Hydri, Iqbal Hussain Udaipurwala, Nadeem Ahmed Sheikh, Sana Muhammad Sadiq et.al.

$3.13 \mathrm{~mm}$ after $4 \mathrm{mg}$ Injection Dexamethasone and 1500 I.U Hyaluronidase weekly injections for 12 weeks ${ }^{20}$. Finally, $3.9 \mathrm{~mm}$ improvement in MIID was seen after $4 \mathrm{mg}(1 \mathrm{ml})$ Injection Betamethasone twice weekly for 8 weeks ${ }^{26}$. Thus, the maximum improvement was $9.38 \mathrm{~mm}$. This is in similar with the results of our study where the mean improvement in MIID in group 'A' was $7.83+/-0.25 \mathrm{mms}$ compared to $10.1+/-0.05 \mathrm{mms}$ in group ' $\mathrm{B}$ '.

The limitations of this study is definitely small number of cases, but it is a pilot study where more cases and experience is required in future. Similar studies are also required to be carried out in other centers of Pakistan to compare the results. Although PRP is very effective but its cost, the trauma and hassle of withdrawing blood on every visit and the wait till the blood is centrifuged and prepared are limiting factors.

\section{CONCLUSION:}

Intraoral injection of platelet rich plasma was more effective than Triamcinolone in improving trismus due to OSMF, however larger studies are required to corroborate these findings.

\section{REFERENCES:}

1. Ray JG, Ranganathan K, Chattopadhyay A. Malignant transformation of oral submucous fibrosis: Overview of histopathological aspects. Oral Surg Oral Med Oral Pathol Oral Radiol. 2016;122:200-9.

2. Chattopadhyay A, Ray JG. Molecular pathology of malignant transformation of oral submucous fibrosis. J Environ Pathol Toxicol Oncol. 2016;35:193-205.

3. Rajendran R. Oral submucous fibrosis: etiology, pathogenesis and future research. WHO Bull OMS. 1994;72(6):986-996

4. Murti P.R., Bhonsle R.B., Gupta P.C., Daftary D.K., Pindborg J.J., Mehta F.S. Etiology of oral submucous fibrosis with special reference to the role of areca nut chewing. J Oral Pathol Med. 1995; 24(4):145-152.

5. Babu S., Bhat R.V., Kumar P.U. A comparative clinicopathological study of oral submucous fibrosis in habitual chewers of pan masala and betel quid. Clin Toxicol. 1996; 34:317-322.

6. Auluck A, Rosin MP, Zhang L. Oral Submucous Fibrosis; a clinically benign but potentially malignant disease: Report of 3 cases and review of literature. www.cda-adc.ca/jcda/vol74/issue-8/735.html [PUBMED]

7. Chole RH, Gondivkar SM, Gadbail AR, Balsaraf S, Chaudhary $\mathrm{S}$, Dhore SV, et al. Review of drug treatment of oral submucous fibrosis. Oral Oncol. 2012; 48:393-8.

8. Pandya S, Chaudhary AK, Singh M, Singh M, Mehrotra R. Correlationof histopathological diagnosis with habits and clinical findings in oralsubmucous fibrosis. Head Neck Oncol. 2009; $1: 10$.

9. Ceena DE, Bastian TS, Ashok L, Annigeri RG. Comparative study ofclinic functional staging of oral submucous fibrosis with qualitativeanalysis of collagen fibers under polarizing microscopy. Indian J DentRes. 2009; 20(3):271-276.

10. Patil S, Maheshwari S. Proposed new grading of oral submucous fibrosisbased on cheek flexibility. J Clin Exp Dent. 2014; 6(3):e255-e258.
11. Gupta M, Pachauri A, Singh SK, Ahuja R, Singh P, Mishra SSS. Recent Advancements in Oral Submucous Fibrosis Management: An Overview. Bangladesh J Dent Res Educ. 2014; 4(2):88-90.

12. Albanese A, Licata ME, Polizzi B, Campisi G. Platelet-rich plasma (PRP) in dental and oral surgery: from the wound healing to bone regeneration. Immun Ageing. 2013;10(1):23.

13. Lin SL, Tsai CC, Wu SL, Ko SY, Chiang WF, Yang JW. Effect of athrocentesis plus platelet-rich plasma and platelet-rich plasma alone in the treatment of temporomandibular joint osteoarthritis: A retrospective matched cohort study. Medicine (Baltimore)2018;97(16):e0477.

14. Marx RE. Platelet-rich plasma: evidence to support its use. J Oral Maxillofac Surg 2004; 62:489-96.

15. Dyavanagoudar SN (2009) Oral Submucous Fibrosis: Review on Etiopathogenesis. J Cancer Sci Ther 1: 072-077. doi:10.4172/1948-5956.1000011[Internet]

16. Yoithapprabhunath TR, Maheswaran T, Dineshshankar J, Anusushanth A, Sindhuja P, Sitra G. Pathogenesis and therapeutic intervention of oral submucous fibrosis. J Pharm Bioallied Sci. 2013; 5(Suppl 1): S85-S88.

17. Chole RH, Patil R. Drug treatment of oral sub mucous fibrosis - a review. Intl J Contemp Med Resr. 2016;3(4):996-998.

18. James L, Shetty A, Rishi D, Abraham M. Management of Oral Submucous fibrosis with Injection of Hyaluronidase and Dexamethasone in grade III Oral Submucous fibrosis: A retrospective study. J Int Oral Health 2015; 7(8):82-85.

19. Gupta J, Srinivasan SV, Jonathan D M. Effiacy of betamethasone, placental extract and hyaluronidase in the treatment of OSMF: A comparative study. e-Journal dentistry;2012;2(1).[Internet]

20. Yadav M, Aravinda K, Saxena VS, Srinivas K, Ratnakar P, Gupta J, Sachdev AS, Shivhare P. Comparison of curcumin with intralesional steroid injections in Oral Submucous Fibrosis - A randomized, open-label interventional study. J Oral Biol Craniofac Res. 2014; 4(3): 169-173.

21. Shaikh AH, Ahmed S, Siddique S, Iqbal N, Hasan SMU, Zaidi SJA, Ali A. Oral submucous fibrosis; Study of cases reported at Dow international medical college hospital in karachi, Pakistan. Professional Med J, 2019;26(2):275-81.

22. Hazarey VK, Erlewad M, Mundhe KA,Ughade SN. Oral submucous fibrosis: study of 1000 cases from central India. J Oral Pathol Med 2007; 36: 12-7

23. Naik SM, Appaji MK, Ravishankara S,Goutham MK, Devi NP, Mushannavar AS, Naik SS. Comparative study of intralesional Triamcinolone Acetonide \& hyaluronidase vs Placental extract in 60 cases of Oral submucous fibrosis. Int J Head Neck Surg 2012; 3(2): 59-65.

24. Patel TL, Singh S. Comparative evaluation of treatment of Oral submucous fibrosis with intralesional injections of Dexamethasone and hyaluronidase with Triamcinolone Acetonide and hyaluronidase. J Cont Med A Dent 2015;3(3): 32-34.

25. Daga D, Singh RK, Pal US, Gurung T, Gangwar S. Efficacy of oral colchicine with intralesional hyaluronidase or triamcinolone acetonide in the Grade II oral submucous fibrosis. Natl J Maxillofac Surg. 2017;8(1):50-54. doi: 10.4103/njms.NJMS_5_17.[PUBMED] 
Comparison of Triamcinolone Versus Platelet Rich Plasma Injection for Improving Trismus in Oral Submucous Fibrosis

26. Singh D, Shashikanth MC, Misra N, Agrawal S. Lycopene and intralesional betamethasone injections in the management of oral submucous fibrosis . J Indian Acad Oral Med Radiol [serial online] 2014 [cited 2016 Sep 1];26:264-8. Available from: http://www.jiaomr.in/text.asp?2014/26/3/264/145000

27. Ferrari M, Zia S, Valbonesi M. A new technique for hemodilution, preparation of autologous platelet-rich plasma and intraoperative blood salvage in cardiac surgery. Int J Artif Organs. 1987;10:47-50.
28. Marx RE. In: Tissue Engineering: Applications in Maxillofacial Surgery and Periodontics. Lynch SE, Genco RJ, Marx RE, editor. Chicago: Quintessence; 1999. Platelet-rich plasma: a source of multiple autologous growth factors for bone grafts; pp. 71-82.

29. Robert E. Marx, DDS. Platelet-Rich Plasma (PRP): What Is PRP and What Is Not PRP?Implant Dentistry, 2001; 10(4):

30. Dayanand AA, Selvam NP. Lycopene in the management of oral submucous fibrosis. Asian J Pharm Clin Res, 2013; 6(3): 58-61. 